\title{
Linkage of cytokine genes to rheumatoid arthritis. Evidence of genetic heterogeneity
}

\begin{abstract}
Sally John, Anne Myerscough, Angela Marlow, Ali Hajeer, Alan Silman, William Ollier, Jane Worthington
\end{abstract}

the major disease locus the remaining genetic effect is likely to result from a number of further loci.

Screening of the genome for non-HLA disease susceptibility genes is currently in progress in RA using microsatellite markers for linkage analysis in large numbers of affected sibling pair (ASP) families. Simulations and experience to date suggest that detection of disease genes with a small $\lambda_{\mathrm{s}}(<1.8)$ will require many hundreds of families and markers at much closer intervals than the average of 11 $\mathrm{cM}$ currently being used. Limited results from French $^{6}$ and British ${ }^{7}$ studies of 200 RA ASP families detected linkage to HLA but no reproducible effects at any other loci. An alternative approach is to apply the same microsatellite technology to sibling pair families to target likely candidate susceptibility genes. The pathology of RA indicates several molecules, which may be of potential importance in disease susceptibility. For example, many cytokines have been shown to be up regulated in the synovial tissue of RA patients ${ }^{8}$ and are produced spontaneously by synovial cells taken from RA patients. To identify the genes that are critical to the development of RA compared with those that are up regulated as part of the inflammatory process, it is necessary to investigate aetiology at a genetic level. Highly polymorphic markers close to gene sequences can be used in family based linkage analysis studies to directly test candidate genes. Investigating candidate genes in this way has the advantage that as the marker selected is genetically very close to the candidate gene, there is a greater chance of detecting even weak linkage.

Many of the proteins implicated in the pathology of RA will be involved as a consequence of the disease process and not a cause of it. One approach to identify molecules involved with the aetiology of RA is to identify genes that are linked to RA. Here we report on linkage analysis of 200 multi-case RA families for 16 potential candidate genes, to test the hypothesis that these genes are linked with RA. Analysis of 200 ASP families using markers within $3 \mathrm{cM}$ of candidate genes will permit genetic effects as small as $\lambda_{\mathrm{s}} 1.5$ to be detected. In view of the clinical and genetic heterogeneity within RA we have stratified the data for; age at onset, sex, seropositive disease, and HLA haplotype sharing.

\section{Methods}

FAMILY MATERIAL

DNA was available from 200 RA families collected for the ARC National Repository for family material. Pedigrees for the first 100
Accepted for publication 7 April 1998 the total genetic component of susceptibilit Thus the majority of the genetic risk of RA is still to be accounted for, although as HLA is 
Table 1 Panel of dinucleotide repeat markers used in linkage analysis studies

\begin{tabular}{llllll}
\hline Genes & Locus & Marker & Position in locus & $\begin{array}{l}\text { Max } \\
\text { Het }\end{array}$ & $\begin{array}{l}\text { Reference or } \\
\text { GDB accession } \\
\text { number }\end{array}$ \\
\hline BCL & 18q21.33 & BCL2 & Unknown & 0.57 & GDB:225700 \\
CD40L & Xq26 & CD40L & 3= UTR & 0.9 & 11 \\
IL6 & 7p21-p15 & D7S493 & 2.8cM & 0.89 & 12 \\
IFN1A, IFN1B & 9p22 & IFNA & Unknown & 0.72 & 13 \\
IFNG & 12q24.1 & IFNG & Intron 1 & 0.67 & 14 \\
IL1A, IL1B IL1RN & 2q13 & IL1A & Intron 5/6 & 0.75 & GDB:157015 \\
IL2 & 4q26-q27 & IL2 & Unknown & 0.89 & 15 \\
IL5R & 3p26-p24 & IL5RA & Unknown & 0.78 & 15 \\
NOS3 & 7q36-q24.1 & NOS3 & Intron 13 & 0.92 & 16 \\
NRAMP, IL8R & 2q35 & VIL1 & 155kb & 0.765 & 17 \\
PI, AACT & 14q13.2 & PI & 5' & 0.9 & 18 \\
\hline
\end{tabular}

Max Het: reported maximum heterozygosity of markers.

families have been published ${ }^{9}$ and are accessible on the ARC ERU web site (address http: //130.88.95.76/natrep.html) together with pedigrees for the second 100 families. All family members were seen and examined according to a standard protocol. Information was also obtained from physician records and rheumatoid factor (RF) measured to classify subjects as having RA if they satisfied the 1987 ACR criteria modified for genetic studies. ${ }^{10}$ In total, 281 affected sib-pairs were included of which 101 sib-pairs were made up from families with between three and seven affected siblings. DNA from both parents was available for 41 families, and from one parent in a further 25 families. Unaffected siblings were genotyped to infer missing parental genotypes. In total 703 individuals were available for genotyping.

CANDIDATE GENE MARKERS

A set of 11 markers with reported heterozygosity ranging from $0.57-0.9$, which mapped within or less than $3 \mathrm{cM}$ from 16 candidate genes has been compiled from published data and data held on the genome data base (GDB) (table 1). The candidate genes include a number of cytokines, interferon $\alpha$ (IFN $\alpha$ ), interferon $\beta$, the interferon $\gamma$ gene cluster, interleukin $1 \alpha$, (IL $1 \alpha)$, interleukin $1 \beta$, interleukin 1 receptor, interleukin 2 (IL2), interleukin 6 (IL6), interleukin 5 receptor (IL5R), and the interleukin 8 receptor (IL8R). The other candidate genes are B-cell lymphoma 2 (BCL2), CD40 ligand (CD40L), natural resistance associated macrophage protein (NRAMP1), endothelial nitric oxide synthase, (NOS3) $\alpha_{1}$ anti-trypsin (PI) and $\alpha_{1}$ antichymotrypsin (AACT).

\section{MICROSATELLITE GENOTYPING}

Semi-automated analysis of microsatellite genotypes was performed using a PE Applied Biosystems 377 DNA sequencer with Genescan analysis and Genotyper software (PE Applied Biosystems). Forward polymerase chain reaction (PCR) primers were fluorescently labelled with either 6-FAM, HEX or TET attached to the $5^{\prime}$ end of the primer during synthesis. Some of the published primer sequences were redesigned to produce products of different sizes that could be incorporated into the panel. Table 2 gives details of the primers. PCRs were performed in a total reaction volume of $10 \mu \mathrm{l}$, containing $50 \mathrm{ng}$ of DNA,
10 pmol of each PCR primer, $4 \mathrm{nmol}$ of each of the four deoxynucleotide triphosphates, 0.2 units Taq polymerase (Bioline) in 1-3 $\mathrm{mM}$ $\mathrm{MgCl}_{2}$ buffer (table 2). The mixture was overlaid with a drop of liquid paraffin. The PCRs were performed in 96 well microtitre plates on Hybaid Omnigene thermal cyclers with 30 cycles of denaturation (one minute, $95^{\circ} \mathrm{C}$ ), primer annealing (one minute, at the annealing temperature indicated in table 2) and extension $\left(45\right.$ seconds at $72^{\circ} \mathrm{C}$ ). Reactions for each marker were performed separately. PCR products were combined into a single pool before electrophoresis, such that all 13 PCR products for a person could be loaded onto a single lane of a gel. Electrophoresis was performed on $0.2 \mathrm{~mm} 4 \%$ polyacrylamide gels run for two hours at $3000 \mathrm{~V}$ with a running temperature of $51^{\circ} \mathrm{C}$. Allele sizes were expressed as mobility units (approximately equivalent to base pairs) as measured by GENESCAN 1.2 analysis software, using TAMRA 350 size standards (PE Applied Biosystems). PCR products from two DNA reference samples were included on every gel as a control to monitor any gel to gel variation.

\section{DATA ANALYSIS}

Sib-pair analysis methods were used to test for excess allele sharing between sibs at all of the loci tested. Sharing at each locus was quantified by the number of alleles shared identical by descent (IBD), alleles shared IBD have the same genotype and the same ancestral origin. Under the null hypothesis of no linkage IBD sharing of 2, 1 or zero alleles is expected to be in the proportion $1: 2: 1$, an increase in the proportion sharing two alleles indicates linkage. As RA has a comparatively late age at disease onset, parental data are often missing, making it difficult to assign IBD sharing directly. The maximum likelihood score (MLS) method was therefore used to estimate allele sharing. The MLS IBD method, ${ }^{19-21}$ allows for uncertainty of IBD assignment resulting from unknown marker haplotypes or missing parental genotype data by inferring most likely IBD sharing probabilities. MLS IBD was carried out in the SPLINK package, version 1.05, (David Clayton MRC Biostatistics unit, Cambridge). In this analysis the IBD data from multiple affected sibships were given the conservative weighting of $2 / n$ where $n$ is the number of affected sibs.

The transmission disequilibrium test ${ }^{22}$ (TDT) is a test of linkage in the presence of an association. Parents heterozygous for a marker are used to test for deviation from random 50:50 transmission from the parent to an affected offspring for one or more alleles of a candidate marker. A maximum likelihood method of TDT was carried out in TRANSMIT, version 2.1 (David Clayton, MRC Biostatistics unit Cambridge). In the TDT, the proband from each pedigree was used in the analysis.

\section{Stratification of the data}

Data were analysed as a complete set and for certain markers where some deviation from 
Table 2 Primer sequences, fluorescent label, and expected size range of PCR products in base pairs (bp) and PCR conditions for the markers in the candidate gene panel

\begin{tabular}{|c|c|c|c|c|c|}
\hline Marker & Label & Product size $b p$ & $\begin{array}{l}\text { Annealing } \\
\text { temperature }\left({ }^{\circ} \mathrm{C}\right)\end{array}$ & $\begin{array}{l}\mathrm{MgCl}_{2} \\
\text { concentration } \\
(\mathrm{mM})\end{array}$ & Primer sequences \\
\hline Il5R & FAM & $83-105$ & 50 & 1.5 & $\begin{array}{l}\text { AATGATCTTTTTCTAGGTAGA } \\
\text { CCTCTGGAGCTTGAGATA }\end{array}$ \\
\hline IL2 & FAM & $113-149$ & 55 & 2 & $\begin{array}{l}\text { AAAGAGACCTGCTAACAC } \\
\text { CCTATGTTGGAGATGTTTAT }\end{array}$ \\
\hline CD40L & FAM & $229-261$ & 50 & 1 & $\begin{array}{l}\text { AAGAAGAGAACTGACTAGCAACG } \\
\text { TCGGACAGTTATTCATTCTCTTT }\end{array}$ \\
\hline $\mathrm{IFN} \gamma$ & HEX & $122-136$ & 40 & 1.5 & $\begin{array}{l}\text { AAAAGATAGTTCCAAAC } \\
\text { TTATAATTATAGCTGTC }\end{array}$ \\
\hline D7S493 & HEX & 193-229 & 55 & 1.5 & $\begin{array}{l}\text { GGAAGTTCCCAGCCATAGTT } \\
\text { GAAAGCACTTACCTACTGAGGATTT }\end{array}$ \\
\hline $\mathrm{IFN} \alpha$ & HEX & $229-251$ & 62 & 1.5 & $\begin{array}{l}\text { CCAGGGCCTTGTCTGTGTGGA* } \\
\text { AAGGTGGAAACCCCCACTGGA }\end{array}$ \\
\hline NOS3 & HEX & $263-319$ & 57 & 1 & $\begin{array}{l}\text { CCCCCGGAGAATGGAGAGGTG* } \\
\text { TGGAAATGACTTGGGGACGCG }\end{array}$ \\
\hline D2S1471 & TET & $81-113$ & 55 & 1.5 & $\begin{array}{l}\text { TACCATTCACACATCGAAGAAC } \\
\text { GATCTCTCCCCCACAATAAAC }\end{array}$ \\
\hline $\operatorname{IL} 1 \alpha$ & TET & $131-145$ & 55 & 1.5 & $\begin{array}{l}\text { ATGTATAGAATTCCATTCCTG } \\
\text { TAAAATCAAGTGTTGATGTAG }\end{array}$ \\
\hline PI & TET & $155-189$ & 55 & 1.5 & $\begin{array}{l}\text { GCATCACACAGAGACACGGAT } \\
\text { TTGCAGGGAGTCAGGTGTATG }\end{array}$ \\
\hline BCL2 & TET & $267-285$ & 62 & 1.5 & $\begin{array}{l}\text { CGGCTAGAAAGGGTCCAGGCG }{ }^{\star} \\
\text { ACTTGGTGGTCGCTGGGGTCC }\end{array}$ \\
\hline
\end{tabular}

${ }^{\star}$ Primer sequences have been redesigned from published sequences.

random inheritance was seen, a number of stratifications were made to the data set as specific genetic effects may be greater in some subgroups of patients. ${ }^{23-25}$ The following criteria were used for stratification:

(1) Age at onset-both siblings having an age of onset of less than 50 years were compared with those where one or both siblings had a later age of onset. It is predicted that stronger genetic effects would be seen in siblings with a younger age at onset.

(2) Sex-As there is evidence that male RA is genetically different, female/male and male/ male sibling pairs were compared with female/ female pairs. There were insufficient male/male pairs for direct comparison.

(3) Disease severity - sibling pairs who both have erosions and who were "ever seropositive" were compared with sibling pairs with a less severe disease. The less severe disease group contained 49 sibling pairs with at least one sibling who had no erosions and 47 sibling pairs with at least one sibling who was "persistently seronegative". There were eight sibling pairs who were both persistently seronegative and only four sibling pairs who both had no erosions.

(4) HLA haplotype sharing-as HLA is known to be the major susceptibility locus in $\mathrm{RA}$, sib-pairs were subdivided into two groups

Table 3 MLS IBD analysis using SPLINK

\begin{tabular}{lllll}
\hline Marker & Het & $\begin{array}{l}\text { Total IBD assigned } \\
0: 1: 2\end{array}$ & $\chi^{2}$ & Equivalent LOD \\
\hline IFN $\alpha$ & 0.68 & $59: 118: 61$ & 0.05 & 0 \\
IFN $\gamma$ & 0.63 & $57: 107: 74$ & 1.8 & 0.39 \\
IL1 $\alpha$ & 0.78 & $49: 106: 49$ & 0 & 0 \\
IL2 & 0.89 & $37: 102: 53$ & 1.73 & 0.38 \\
IL5R & 0.79 & $48: 89: 60$ & 1.84 & 0.39 \\
D7S493 (IL6) & 0.87 & $50: 105: 51$ & 0.02 & 0 \\
BCL2 & 0.36 & $56: 100: 55$ & 0.12 & 0.03 \\
D2S1471 (NRAMP,IL8R) & 0.79 & $29: 54: 22$ & 0 & 0 \\
NOS3 & 0.91 & $50: 75: 47$ & 0.25 & 0.05 \\
PI & 0.85 & $55: 99: 58$ & 0.49 & 0.1 \\
${ }^{*}$ CD40L & 0.75 & $50: 56$ & 0 & 0
\end{tabular}

Estimated heterozygosity (Het) is calculated from parental allele frequencies. Equivalent LOD: $\chi^{2}$ can be converted to a LOD score by $\chi^{2} / 4.86 .{ }^{\star} \mathrm{CD} 40 \mathrm{~L}$ is on the $\mathrm{X}$ chromosome, therefore $1: 1$ allele sharing is shown from the maternal chromosome, under random inheritance this is 50:50. by IBD status at HLA. One group of families showing stronger evidence of linkage to HLA was compared with those discordant for HLA background-that is, sharing 1 or zero HLA haplotypes. It would also be interesting to compare siblings who were "shared epitope" positive with those who were "shared epitope" negative, however the numbers of "shared epitope" negative pairs (14) was too small to analyse.

\section{Results}

WHOLE DATA SET

Estimated IBD sharing generated by SPLINK did not generate any significant LOD scores for any of the markers tested (table 3) although a small increase in sharing of two alleles IBD was seen for markers IL2, IL5R, and IFN $\gamma$.

\section{STRATIFICATION OF THE DATA SET}

$\mathrm{RA}$ is an extremely heterogeneous condition, and as it is expected that different genes may contribute to variation in disease expression, the whole data set was stratified as described in the methods. MLS IBD analysis was performed on the subgroups for markers IL5R, IL2, and IFN $\gamma$, where some deviation from random sharing had been seen in the whole data set. No significant deviation from random allele sharing was seen in the sibling pairs stratified by age at onset of RA (table 4 (A)).

Two LOD scores were significant at $\mathrm{p}<0.05$ level in the patient group stratified by sex (table 4(B)). IL5R showed an increase in two alleles sharing in the all female pairs (LOD $0.9, \mathrm{p}=$ 0.03 ) and a similar increase was detected for IFN $\gamma$ in pairs with a male - that is, male/male and male/female pedigrees (LOD $0.9, \mathrm{p}=$ 0.03).

The data set was also subdivided to test for linkage in sibling pairs with more severe disease. The strongest evidence of linkage was for IL2 in the group with less severe disease (LOD 1.05, p = 0.02 (table 4 (C)). Many patients in this group were seronegative and to 
Table 4 MLS IBD analysis in patient subgroups for IFN $\gamma, I L 5 R$, and IL2

\begin{tabular}{|c|c|c|c|c|c|}
\hline Marker & Patient group & $\begin{array}{l}\text { Total IBD } \\
\text { assignment } \\
0: 1: 2\end{array}$ & $\chi^{2}$ & $\begin{array}{l}\text { Equivalent } \\
\text { LOD }\end{array}$ & $p$ Value \\
\hline \multicolumn{6}{|l|}{ (A) } \\
\hline \multirow[t]{2}{*}{$\mathrm{IFN} \gamma$} & Early onset & $29: 67: 37$ & 0.48 & 0.1 & NS \\
\hline & Late onset & $24: 39: 38$ & 2.59 & 0.56 & 0.08 \\
\hline \multirow[t]{2}{*}{ IL5R } & Early onset & $33: 59: 40$ & 0.97 & 0.2 & NS \\
\hline & Late onset & $21: 43: 28$ & 0.74 & 0.16 & NS \\
\hline \multirow[t]{2}{*}{ IL2 } & Early onset & $17: 59: 32$ & 2.8 & 0.6 & 0.07 \\
\hline & Late onset & $20: 42: 19$ & 0 & 0 & NS \\
\hline \multicolumn{6}{|l|}{ (B) } \\
\hline \multirow[t]{2}{*}{$\mathrm{IFN} \gamma$} & All female & $33: 64: 31$ & 0 & 0 & NS \\
\hline & female $/$ male, male $/$ male & $24: 43: 42$ & 4.43 & 0.96 & 0.03 \\
\hline \multirow[t]{2}{*}{ IL5R } & All female & $26: 40: 38$ & 4.20 & 0.91 & 0.03 \\
\hline & female/male male/male & $23: 49: 23$ & 0 & 0 & NS \\
\hline \multirow[t]{2}{*}{ IL2 } & All female & $23: 52: 26$ & 0.07 & 0 & NS \\
\hline & female/male, male/male & $13: 51: 27$ & 2.50 & 0.54 & 0.08 \\
\hline \multicolumn{6}{|c|}{ 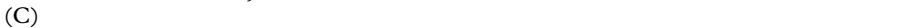 } \\
\hline \multirow[t]{2}{*}{$\mathrm{IFN} \gamma$} & Severe disease & $21: 36: 22$ & 0.16 & 0.04 & NS \\
\hline & & $35: 72: 51$ & 1.7 & 0.38 & NS \\
\hline \multirow[t]{2}{*}{ IL5R } & Severe disease & $21: 34: 21$ & 1.02 & 0.2 & NS \\
\hline & & $31: 62: 39$ & 0.8 & 0.19 & NS \\
\hline \multirow[t]{2}{*}{ IL2 } & Severe disease & $16: 38: 13$ & 0 & 0 & NS \\
\hline & & $19: 64: 41$ & 4.85 & 1.05 & 0.02 \\
\hline \multicolumn{6}{|c|}{ Her } \\
\hline \multirow[t]{2}{*}{$\mathrm{IFN} \gamma$} & HLA concordant & $17: 33: 23$ & 0.76 & 0.18 & NS \\
\hline & HLA discordant & $32: 52: 38$ & 0.81 & 0.18 & NS \\
\hline \multirow[t]{2}{*}{ IL5R } & HLA concordant & $16: 30: 20$ & 0.48 & 0.1 & NS \\
\hline & HLA discordant & $24: 41: 30$ & 1.0 & 0.24 & NS \\
\hline \multirow[t]{2}{*}{ IL2 } & HLA concordant & $12: 35: 14$ & 0.1 & 0.02 & NS \\
\hline & HLA discordant & $20: 50: 29$ & 1.16 & 0.25 & NS \\
\hline
\end{tabular}

test if IL2 is linked specifically to seronegative RA we analysed sibling pairs where one or both were seronegative. Despite the smaller sample size of this subgroup, the LOD score was maintained at $1.07(\mathrm{p}=0.02)$ with final total IBD sharing assignments of (0-IBD: 1-IBD: 2-IBD) 9:35:25. No significant deviation from random allele sharing was seen in the families stratified by HLA sharing (table 4(D)). The marker for NRAMP (D2S1471) was also analysed in the HLA subgroups as some weak evidence of linkage had previously been shown in a smaller set of ARC families ${ }^{26}$ and in patients discordant for HLA haplotypes. ${ }^{27}$ In this larger data set, no deviation from random sharing was observed (data not shown).

TDT ANALYSIS

As IFN $\gamma$, IL5R, and IL2 are all markers within the gene sequence, evidence of linkage to these genes would be further supported by demonstration of an association between specific alleles of the microsatellite marker and RA, result-

Table 5 TDT analysis of 16 alleles of the IL2 microsatellite in the erosion and/or RF negative subset of patients

\begin{tabular}{llll}
\hline $\begin{array}{l}\text { Allele size } \\
(b p)\end{array}$ & $\begin{array}{l}\text { Observed } \\
\text { transmission to } \\
\text { offspring }\end{array}$ & $\begin{array}{l}\text { Expected } \\
\text { transmission to } \\
\text { offspring }\end{array}$ & \\
\hline 113 & 28 & 27 & \\
119 & 1 & 1 & \\
121 & 3 & 4 & \\
123 & 6 & 5 & \\
125 & 8 & 8 & \\
127 & 49 & 58 & \\
129 & 22 & 22 & \\
131 & 63 & 62 & \\
133 & 34 & 33 & \\
135 & 73 & 73 & \\
137 & 32 & 38 & \\
139 & 36 & 36 & \\
141 & 31 & 25 & \\
& & 8 & \\
143 & 14 & 2 & \\
145 & 2 & 1 & \\
147 & 2 & & \\
\hline
\end{tabular}

ing from linkage disequilibrium with a potential functional polymorphism in the gene. Markers for IL5R, IFN $\gamma$, and IL2 were therefore analysed by TDT in the subsets of patients where there was some preliminary evidence of linkage $(p \leqslant 0.05)$. No evidence of linkage to a particular allele of IL5R or IFN $\gamma$ was seen (data not shown). There were 16 alleles observed for the IL2 microsatellite. Table 5 shows TDT analysis of observed and expected transmission of each of these alleles. Two alleles of the IL 2 marker that were only $2 b p$ apart (141 and 143bp) appeared to be inherited by affected offspring more often than expected. If the transmission of these two alleles were combined, a $\chi^{2}$ of 4.37 ( $p=0.05$ one degree of freedom) was observed.

\section{Discussion}

We have investigated the contribution of a number of candidate gene loci to RA susceptibility using linkage analysis methods. Analysis of the data before stratification showed no significant deviation from expected allele sharing for any of the markers tested. Although the results were negative and a major contribution for these genes can be excluded, the actual effect of each locus that can be excluded in this data set varies depending upon a number of factors. Over 200 sibling pairs have been genotyped in this investigation, but because the markers were not fully informative and also because of an absence of parental information, the amount of information contributed by the families is variable. It is possible to exclude a genetic effect $(\lambda s=1.5)$ for the following genes; IFN $\alpha$, IL2, IL5R, NRAMP, IL8R, NOS3, and PI. For IFN $\gamma$, IL $1 \alpha$, and CD40L, which were less informative, a genetic effect with a $\lambda_{\mathrm{s}}=1.7$ can be excluded. The heterozygosity of BCL2 (0.36), calculated from our data set, was much lower than the reported heterozygosity, therefore, it is only possible to exclude a $\lambda s=1.85$. We conclude that none of the genes tested in this investigation has a role as great as HLA, which was calculated to have a $\lambda_{\mathrm{s}}$ of 1.8 , based on analysis of the first 100 families in the ARC National Repository. ${ }^{5}$

A possible reason for failing to detect weak genetic effects in complex disease is heterogeneity. To deal with this, the data were subdivided into a number of more homogeneous subsets and analysis was repeated for IL5R, IFN $\gamma$, and IL2, where some deviation from random allele sharing was observed. For each of these genes, an increase in allele sharing $(\mathrm{p}<0.05)$ was observed in a patient subgroup.

One way of supporting the initial finding of linkage is to demonstrate linkage disequilibrium between the marker and a potential functional polymorphism within the gene. TDT detects linkage in the presence of an association. There was some evidence that the larger alleles of the IL2 microsatellite were being transmitted to affected offspring in the patient subgroup with less severe disease, more often than expected. This provides some preliminary evidence that alleles of the IL2 microsatellite may be in linkage disequilibrium with a functional polymorphism in the gene. The 
evidence for linkage was seen most convincingly in seronegative RA. HLA associations have already suggested that patients with seronegative RA may represent a disease with a different genetic background. ${ }^{28}$ IL2 is primarily a Th1 cytokine produced by both naive and activated CD4+ve cells, and functional polymorphisms within regulatory or coding sequences could lead to changed immune function. Interestingly, IL2 knockout mice develop severe autoimmune disease and lymphocyte proliferation, ${ }^{29}$ suggesting functions of IL2 are more diverse than previously realised.

The TDT analysis did not support an association with both IFN $\gamma$ or IL5R alleles and RA; there are a number of explanations. Highly polymorphic microsatellites with many alleles are not always in linkage disequilibrium with less polymorphic markers, for example, functional biallelic point mutations, which are genetically very close. ${ }^{30}{ }^{31}$ Linkage also extends much further than linkage disequilibrium and the linkage finding may be true but result from linkage, not with the candidate gene, but with a different gene in the same region. It is also possible that these results may be false positives. In the initial analysis on 200 families, no correction for multiple testing was made, as there was an a priori hypothesis for investigating each of the candidate genes. However, for each marker tested in the patient subsets, nine separate analysis tests were performed. It is possible that for the three genes tested in this way that 1-2 false positive results would be seen at a 5\% significance level. Replication of these results in further data sets or the demonstration of an association between RA and a functional polymorphism of the genes is required to confirm which, if any of these findings are because of genuine linkage. This study has identified three genes worthy of further study and clearly illustrates the importance of considering genetic heterogeneity when investigating a complex disease such as RA.

1 Silman AJ, McGregor AJ, Thomson W, Holligan S, Carthy $\mathrm{D}$, Farhan A, et al. Twin concordance rates for rheumatoid arthritis: results from a nationwide study. Br J Rheumato 1993;32:903-7.

2 Deighton CM, Walker DJ. The familial nature of Rheumatoid Arthritis. Ann Rheum Dis 1991;50:62-5.

3 Risch N. Assessing the role of HLA-linked and unlinked determinants of disease. Am J Hum Genet 1987;40:1-14.

4 Gregerson PK, Silver J, Winchester RJ. The shared epitope hypothesis. An approach to understanding the molecular genetics of susceptibility to rheumatoid arthritis. Arthritis Rheum 1987;30:1205-13.

5 Marlow A, John S, Hajeer A, Ollier W, Silman A, Worthington J. The sensitivity of different analytical methods to detect disease susceptibility genes in RA sibling pair famidetect disease susceptibility genes

6 Cornelis F, Faure S, Martinez M, Fritz P, Dib C, Prud'homme JF, et al. Systematic screening of the entire genome in rheumatoid arthritis families reveals three major susceptibility loci. [Abstract]. Arthritis Rheum 1996;39 (suppl):73.

7 Hardwick LJ, Walsh S, Butcher, Nicod A, Shatford J, Bell J, Lathrop $\mathrm{M}$, et al. Mapping and characterization of the genes involved in rheumatoid arthritis. [Abstract]. $\mathrm{Br} \mathrm{J}$ Rheumatol 1996;35 (suppl):10.

8 Feldman M, Brennan FM, Williams RO, Cope AP, Gibbons DL, Katsikis PD, et al. Evaluation of the role of cytokines in autoimmune disease: The importance of TNF $\alpha$ in rheumatoid arthritis. Progress in Growth Factor Research $1992 ; 4: 247-55$

9 Worthington J, Ollier WER, Leach MK, Smith I, Hay EM, Thomson W, et al. The Arthritis and Rheumatism Council's National Repository of family material: pedigrees from the first 100 rheumatoid arthritis families containing affected sibling pairs. Br J Rheumatol 1994;33:970-6.

10 McGregor AJ, Bamber S, Silman AJ. A comparison of the performance of different methods of disease classification for rheumatoid arthritis. Results and analysis from a nationwide twin study. J Rheumatol 1994;21:1420-6

11 Allen RC, Spriggs MK, Belmont JW. Dinucleotide repeat polymorphism in the human CD40 ligand gene. Hum Mol polymorphism in the $1993 ; 2: 828$.

12 Gyapay G, Morisette J, Vignal A, Dib C, Fizames C, Millasseau P, et al. The 1993-94 Genethon human genetic linkage map. Nat Genet 1994;7:246-339.

13 Kwiatkowski DJ, Diaz MO. Dinucleotide repeat polymorphism at the IFNA locus (9p22). Hum Mol Genet 1992;1: 658.

14 Ruiz-Linares A. Dinucleotide repeat polymorphism in the interferon -gamma (IFNG) gene. Hum Mol Genet 1993;2: 1508.

15 Epplen C, Frank G, Gomolka M, Nagy M, Nurnberg P, Epplen JT. Dinucleotide repeat polymorphisms in the IL2 and IL5RA genes. Hum Mol Genet 1994;3 :679.

16 Nadaud S Bonnardeaux A Lathrop M Soubrier F. Gene structure and polymorphism and mapping of the human endothelial nitric oxide synthase gene. Biochem Biophys Res Commun 1994;198:1027-33.

17 Copeman JB, Cucca F, Hearne CM, Cornell RJ, Reed PW, Ronningen KS, et al. Linkage disequilibrium mapping of a type 1 diabetes susceptibility gene (IDDM7) to chromosome 2q31-q33. Nat Genet 1995;9:80-5

18 Byth BC, Cox DW. A (CA)n repeat polymorphism at the 5, end of the $\alpha$-1-antitrypsin gene (PI). Hum Mol Genet 1993;2:1752.

19 Risch N. Linkage strategies for genetically complex traits. II: The power of affected relative pairs. Am J Hum Genet 1990;46:229-41.

20 Holmans P. Asymptotic properties of affected sib-pair linkage analysis. Am J Hum Genet 1993;52:362-74.

21 Holmans P, Clayton D. Efficiency of typing unaffected relatives in an affected sib-pair linkage study with single-locus and multiple tightly linked markers. Am J Hum Genet 1995;57:1221-32.

22 Spielman RS, McGinnis RE, Ewens WJ. Transmission test or linkage disequilibrium: the insulin gene region and insulin-dependent diabetes mellitus (IDDM). Am J Hum Genet 1993;52:506-16.

23 Hajeer A, John S, Ollier W, Silman AJ, Dawes P, Hassell A, et al. TNF microsatellite haplotypes are different in male and female RA patients. J Rheumatol 1997;240:217-19.

24 Lynn AH, Kwoh CK, Venglish CM, Aston CE, Chakravarti A. Genetic epidemiology of rheumatoid arthritis. Am J Hum Genet 1995; 7:150-9.

25 Meyer JM, Jinfeng H, Singh R, Moxeley G. Sex influences on the penetrance of HLA shared epitope genotypes for rheumatoid arthritis. Am J Hum Genet 1996;58:371-83.

26 Shaw MA, Clayton D, Atkinson SE, Williams H, Miller N, Sibthorpe D, et al. Linkage of rheumatoid arthritis to the candidate gene NRAMP on 2q35. J Med Genet 1996;33: $1-6$.

27 John S, Marlow A, Hajeer A, Ollier W, Silman A, Worthington J. Linkage and association studies of the natural resistance associated macrophage protein locus in rheumatoid arthritis. J Rheumatol 1997;24:452-7.

28 Ploski R, Mellbye OJ, Ronningen KS, Forre O, Thorsby E.Seronegative and weakly seropositive rheumatoid arthritis differs from clearly seropositive rheumatoid arthritis in HLA class II associations. J Rheumatol 1994;21:1397-402.

29 Sadlack B, Lohler J, Schorle H, Klebb G, Haber H, Sickel E, et al. Generalized autoimmune disease in interleukin-2 deficient mice is triggered by an uncontrolled activation and proliferation of $\mathrm{CD} 4+\mathrm{T}$ cells. Eur J Immunol 1995;25:3035-9.

30 Peterson AC, Di Rienzo A, Lehesjoki AE, de la Chapelle A, Slatkin M, Friemer NB. The distribution of linkage disequilibrium over anonymous genome regions. Hum Mol Genet 1995;4:887-94.

31 McKenzie CA, Julier C, Forrester T, McFarlane-Anderson N, Keavney B, Lathrop GM, et al. Segregation and linkage analysis of serum angiotensin I-converting enzyme levels: evidence for two quantitative-trait loci. Am J Hum Genet 1995;57:1426-35. 